\title{
Comparison of laser and anti VEGF therapy in treatment of diabetic macular edema
}

\begin{abstract}
Purpose: The purpose of this study was to compare the efficacy of treatment modalities of diabetic macular edema.

Methods: This interventional study was done from August 2018 to May 2019 at Madinah Teaching Hospital, Faisalabad. 30 subjects were selected by Convenient Sampling technique, aged between 30-70 years, male and female gender was included. Study design was interventional. Eyes were randomized to grid laser photocoagulation $(\mathrm{N}=15)$ and AntiVEGF $(\mathrm{N}=15)$. Consent was taken from the selected participants with diabetic macular edema. Visual acuity and retinal thickness were recorded before and after the treatment therapies. Data analysis was done by latest SPSS version.
\end{abstract}

Results: A total of 30 patients were included in our interventional study. Intravitreal Avastin improved BCVA most significantly (OR: $+7.0195 \% \mathrm{CI}$ (2.56 to 11.39)) in 1 month followup and Laser less significantly $(+8.19(5.07$ to 11.96$))$ in one month follow up. Intravitreal Avastin decreased retinal thickness most significantly (-111.34 (-254.61 to 37.93)) in one months and Laser decreased less significantly.SPSS showed that significant result less than 0.005 .

Conclusion: Avastin therapy was found more effective in diabetic macular edema management than the Laser therapy in follow-ups.

Keywords: grid laser photocoagulation, Anti-VEGF (Bevacizumab), diabetic macular edema, diabetic retinopathy
Volume IO Issue I - 2020

\author{
Hira Anwar,' Iqra Khalil, ${ }^{2}$ Saba Akram, ${ }^{3}$ Asma \\ Batool, ${ }^{4}$ Samia Iqbal ${ }^{5}$ \\ 'Madinah Teaching Hospital, Faisalabad, Pakistan \\ ${ }^{2}$ ziz Fatima Hospital, Faisalabad, Pakistan \\ ${ }^{3}$ Lecturer in University of Lahore, Pakistan \\ ${ }^{4}$ Lecturer in department of optometry, The University of Lahore, \\ Pakistan \\ ${ }^{5}$ University of Lahore Teaching Hospital, Pakistan
}

Correspondence: Hira Anwar, Madinah Teaching Hospital, Pakistan, Tel 03330946876, Email Heerrajpoot99@yahoo.com

Received: December 30, 2019 | Published: January 21, 2020

\section{Introduction}

Diabetic macular edema is one of the main features of diabetic retinopathy which is associated with diabetes mellitus. Diabetic macular edema is characterized by increased vascular leakage in central part of retina and leading cause of serious central visual impairment in diabetic patients. ${ }^{1}$ The common characteristic is the increase in levels of vascular endothelial growth factor (VEGF), which is responsible for the disruption of the inner blood-retinal barrier. ${ }^{2}$ Disruption of the blood retinal barrier leads to the accumulation of subretinal and intraretinal fluid, which in turn alters the macular structure and function. If diabetic macular edema is left untreated, the potential loss of vision from diabetic macular edema poses a significant concern with regard to reduction inhealth-related quality of life affecting the socioeconomic status of community. ${ }^{3}$ A population-based study in south Wisconsin projected that the prevalence of diabetic macular edema after 20 years ofknown diabetes was around $28 \%$ in both type I and II diabetes. ${ }^{4}$ Assessment of Diabetic Macular Edema with Visual Impairment (PREVAIL) study of patients with diabetes mellitus in seven European countries, concluded that Visual Impairment due to Diabetic macular Edema is a significant complication of Diabetes Mellitus. Progression of diabetic retinopathy can be prevented through control of blood pressure and diabetes.It is well established that the widely used treatments that reduce DME can improve or stabilize visual acuity. ${ }^{5}$ Early treatment option for patients with visual impairment due to diabetic macular edema was laser photocoagulation. In laser photocoagulation study, two macular laser treatment techniques were defined: focal and grid, both performed between 500 and 300 microns from the fovea but not within the papillary border. In focal/grid photocoagulation laser shots are applied to leaking micro aneurysms directly or delivered in grid pattern on the edematous part of the retina. ${ }^{6}$ The management option for patients having diabetic macular edema have expanded in recent years. For many years it has been established that vascular endothelial growth factor plays a role in the creation of retinal ischemia and increase vascular permeability that gives rise to macular edema. ${ }^{7}$ Anti VEGF is new treatment modality in management of diabetic macular edema. In anti VEGF therapy, an antibody is administered as intravitreal injections. ${ }^{8}$ Given the substantial burden of Visual Impairment due to Diabetic Macular Edema and the developing options and clinical evidence for treatment, it is important to regularly compare the relative efficacy of available therapies. This study compares the relative efficacy of current firstline therapies that have current data.

\section{Methodology}

This interventional study was conducted from Sep 2018 to May 2019 , to compare the Laser photocoagulation and Anti-VEGF therapies in treatment of diabetic macular edema. Study was conducted at Ophthalmology Department of Medina teaching hospital Faisalabad. Convenient sampling technique was applied. Total subjects $(\mathrm{N}=30)$ were included in this study. Patients with diabetic macular edema that was detected clinically with best corrected visual acuity (BCVA) less than 6/12or 0.5 logMar and Central retinal thickness (CRT) $250 \mu \mathrm{m}$ were included. Patient's age ranging from 30-70 years were included. Patients having other retinal disease, corneal opacities patients having bleeding disorder, lens opacities, patients with recent MI stroke and systemic diseases were excluded in this study. Complete history was taken, complete eye examination done by slit lamp and visual acuity was measured by ETDRs chart and central retinal thickness by performing OCT on patients. ETDRs chart was used to asses visual acuity outcomes after treatment therapies (laser photocoagulation and Anti VEGF injections) after 1 month follow ups. Post procedure OCT was done on all patients 1stmonth after injection and this was when 
outcome was determined on the basis of change in macular thickness (as mentioned in operational definition). OCT was carried out to ensure effectiveness of the therapiesfor diabetic macular edema. Data was entered into SPSS and analyzed by using t-test.

\section{Results}

In avastin therapy out of 15 patients $11(73.3 \%)$ were male and $4(26.7 \%)$ are female. Out of 15 patients the $7(46.7 \%)$ had visual acuity $0.2-0.3$ before injection dose of avastin and 5(33.3) have 0.4 V.A and remaining 3(20.0) have $0.5 \mathrm{~V}$.A. Out of 15 patients the 5(33.3\%) had V.A 0.4 after injection dose of avastin and $6(40.0 \%)$ had 0.5 V.A and remaining $4(26.7 \%)$ had 0.6 V.A. Out of 15 patients the $12(80.0 \%)$ had macular thickness $321-380 \mu \mathrm{m}$ before avastin and $3(20.0 \%)$ had $381-420$ before avastin. Out of 15 patients the $9(60.0 \%)$ had macular thickness $250-280 \mu \mathrm{m}$ after avastin and $4(26.7 \%)$ had $281-320 \mu \mathrm{m}$

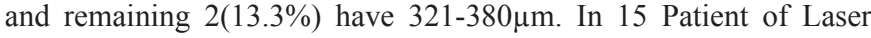
$9(60.0 \%)$ were male and $6(40.0 \%)$ were female. Out of 15 patients $8(53.3 \%)$ have visual acuity $0.2-0.3$ before Laser and $7(46.7 \%)$ have 0.4 visual acuity. Out of 15 patients $13(86.7 \%)$ have visual acuity $0.2-0.3$ after Laser and $2(13.3 \%)$ had 0.4 visual acuity. Out of 15 patients $4(26.7 \%)$ had macular thickness $250-280 \mu \mathrm{m}$ before laser

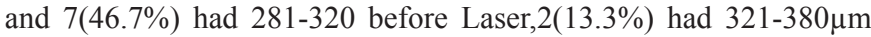
and remaining $2(13.3 \%)$ had macular thickness. Out of 15 patients $12(80.0 \%)$ had macular thickness $250-280 \mu \mathrm{m}$ after laser and $1(6.7 \%)$ had 321-380 $\mu \mathrm{m}$ after Laser,2(13.3\%) had 381-420.SPSS showed that significant results less than 0.005 .

Table I Visual acuity before avastin

\begin{tabular}{llllll}
\hline & & Frequency & Percent & $\begin{array}{l}\text { Valid } \\
\text { percent }\end{array}$ & $\begin{array}{l}\text { Cumulative } \\
\text { percent }\end{array}$ \\
\hline Valid & $0.2-0.3$ & 7 & 46.7 & 46.7 & 46.7 \\
& 0.4 & 5 & 33.3 & 33.3 & 80 \\
& 0.5 & 3 & 20 & 20 & 100 \\
& Total & 15 & 100 & 100 &
\end{tabular}

Above Table 1 shows that out of 15 patients the 7(46.7\%) have visual acuity $0.2-0.3$ before injection dose of avastin and 5(33.3) are male and $4(26.7 \%)$ are female.

Table 2 Visual acuity after avastin

\begin{tabular}{llllll}
\hline & & Frequency & Percent & $\begin{array}{l}\text { Valid } \\
\text { percent }\end{array}$ & $\begin{array}{l}\text { Cumulative } \\
\text { percent }\end{array}$ \\
\hline Valid & 0.4 & 5 & 33.3 & 33.3 & 33.3 \\
& 0.5 & 6 & 40 & 40 & 73.3 \\
& 0.6 & 4 & 26.7 & 26.7 & 100 \\
& Total & 15 & 100 & 100 & \\
\hline
\end{tabular}

Above Table 2 shows that out of 15 patients the $4(100 \%)$ have visual acuity 0.6 after injection dose of avastin and 5(33.3) are male and $4(26.7 \%)$ are female.

Table 3 Retinal Nerve Fiber Layer Thickness before avastin

\begin{tabular}{llllll}
\hline & & Frequency & Percent & $\begin{array}{l}\text { Valid } \\
\text { percent }\end{array}$ & $\begin{array}{l}\text { Cumulative } \\
\text { percent }\end{array}$ \\
\hline Valid & $321-380$ & 12 & 80 & 80 & 80 \\
& $381-420$ & 3 & 20 & 20 & 100 \\
& Total & 15 & 100 & 100 &
\end{tabular}

Above Table 3 shows that out of 15 patients the $12(80 \%)$ have Macular thickness 321-380 before laser and 3(20\%) have 381-420 before Laser, have macular thickness.

Table 4 Retinal Nerve Fiber Layer Thickness After avastin

\begin{tabular}{llllll}
\hline & & Frequency & Percent & $\begin{array}{l}\text { Valid } \\
\text { percent }\end{array}$ & $\begin{array}{l}\text { Cumulative } \\
\text { percent }\end{array}$ \\
\hline Valid & $250-280$ & 9 & 60 & 60 & 60 \\
& $281-320$ & 4 & 26.7 & 26.7 & 86.7 \\
$321-380$ & 2 & 13.3 & 13.3 & 100 \\
Total & 15 & 100 & 100 & \\
\hline
\end{tabular}

Above Table 4 shows that out of 15 patients the $9(60 \%)$ have macular thickness 250-280 after avastin and 4(26.7\%) have 281-320 after avastin, 2(13.3\%) have 321-380.

Table 5 Descriptive statistics

\begin{tabular}{|c|c|c|c|c|c|}
\hline & $\mathbf{N}$ & Minimum & Maximum & Mean & $\begin{array}{l}\text { Std. } \\
\text { deviation }\end{array}$ \\
\hline Age & 15 & 1 & 3 & 1.9333 & 0.88372 \\
\hline Gender & 15 & 1 & 2 & 1.2667 & 0.45774 \\
\hline $\begin{array}{l}\text { V.A.before. } \\
\text { Avastin }\end{array}$ & 15 & 1 & 3 & 1.7333 & $0.7988 I$ \\
\hline $\begin{array}{l}\text { V.A.After. } \\
\text { Avastin }\end{array}$ & 15 & 2 & 4 & 2.9333 & $0.7988 I$ \\
\hline $\begin{array}{l}\text { RNFL. } \\
\text { Thickness. } \\
\text { before.avastin }\end{array}$ & 15 & 3 & 4 & 3.2 & 0.41404 \\
\hline $\begin{array}{l}\text { RNFL. } \\
\text { Thickness. } \\
\text { After.Avastin }\end{array}$ & 15 & 1 & 3 & 1.5333 & 0.74322 \\
\hline $\begin{array}{l}\text { Valid N } \\
\text { (listwise) }\end{array}$ & 15 & & & & \\
\hline
\end{tabular}

This Table 5 shows that mean of RNFL changed before and after application of Avastin. It decreased after avastin as $15333 \pm 0.74322$. And visual acuity was also changed or improved after avastin. Its mean was increased as $2.933 \pm 0.79881$ after avastin.

\section{Frequencies analysis of laser phtocoagulations}

Table 6 Visual acuity before laser

\begin{tabular}{llllll}
\hline & & Frequency & Percent & $\begin{array}{l}\text { Valid } \\
\text { percent }\end{array}$ & $\begin{array}{l}\text { Cumulative } \\
\text { percent }\end{array}$ \\
\hline Valid & $0.2-0.3$ & 8 & 53.3 & 53.3 & 53.3 \\
& 0.4 & 7 & 46.7 & 46.7 & 100 \\
& Total & 15 & 100 & 100 &
\end{tabular}

Above Table 6 shows that out of 15 patients the 8(53.3\%) have visual acuity $0.2-0.3$ before Laser and $7(46.7 \%)$ have 0.4 visual acuity.

Table 7 Visual Acuity after Laser

\begin{tabular}{llllll}
\hline & & Frequency & Percent & $\begin{array}{l}\text { Valid } \\
\text { percent }\end{array}$ & $\begin{array}{l}\text { Cumulative } \\
\text { percent }\end{array}$ \\
\cline { 3 - 6 } Valid & $0.2-0.3$ & 13 & 86.7 & 86.7 & 86.7 \\
& 0.4 & 2 & 13.3 & 13.3 & 100 \\
& Total & 15 & 100 & 100 & \\
\hline
\end{tabular}


Above Table 7 shows that out of 15 patients the 13(86.7\%) have visual acuity 0.2-0.3 after Laser and 2(13.3\%) have 0.4 visual acuity.

Table 8 Retinal nerve fiber layer thickness before laser

\begin{tabular}{llllll}
\hline & & Frequency & Percent & $\begin{array}{l}\text { Valid } \\
\text { percent }\end{array}$ & $\begin{array}{l}\text { Cumulative } \\
\text { percent }\end{array}$ \\
\hline Valid & $250-280$ & 4 & 26.7 & 26.7 & 26.7 \\
& $281-320$ & 7 & 46.7 & 46.7 & 73.3 \\
$321-380$ & 2 & 13.3 & 13.3 & 86.7 \\
$381-420$ & 2 & 13.3 & 13.3 & 100 \\
Total & 15 & 100 & 100 & \\
\hline
\end{tabular}

Above Table 8 shows that out of 15 patients the $4(26.7 \%)$ have retinal nerve fiber layer thickness $250-280$ before laser and 7(46.7\%) have 281-320 before Laser, 2(13.3\%) have 321-380 and remaining 2(13.3\%) have RNFL thickness.

Table 9 Retinal nerve fiber layer thickness after laser

\begin{tabular}{llllll}
\hline & & Frequency & Percent & $\begin{array}{l}\text { Valid } \\
\text { percent }\end{array}$ & $\begin{array}{l}\text { Cumulative } \\
\text { percent }\end{array}$ \\
\hline Valid & $250-280$ & 12 & 80 & 80 & 80 \\
& $321-380$ & 1 & 6.7 & 6.7 & 86.7 \\
$381-420$ & 2 & 13.3 & 13.3 & 100 \\
Total & 15 & 100 & 100 &
\end{tabular}

Above Table 9 shows that out of 15 patients the $12(80.0 \%)$ have retinal nerve fiber layer thickness250-280 after laser and $1(6.7 \%)$ have 321-380 after Laser, 2(13.3\%) have 381-420 (Table 10).

Table 10 T-Test paired samples statistics

\begin{tabular}{|c|c|c|c|c|c|}
\hline & & Mean & $\mathbf{N}$ & $\begin{array}{l}\text { Std. } \\
\text { deviation }\end{array}$ & $\begin{array}{l}\text { Std. error } \\
\text { mean }\end{array}$ \\
\hline \multirow[t]{2}{*}{ Pair I } & V.A.before.laser & 1.4667 & 15 & 0.5164 & 0.13333 \\
\hline & V.A.after.laser & 1.1333 & 15 & 0.35187 & 0.09085 \\
\hline \multirow[t]{2}{*}{ Pair 2} & $\begin{array}{l}\text { RNFL.thickness. } \\
\text { before.laser }\end{array}$ & 2.1333 & 15 & 0.99043 & 0.25573 \\
\hline & $\begin{array}{l}\text { RNFL.thickness. } \\
\text { after.laser }\end{array}$ & I.5333 & 15 & I. 12546 & 0.29059 \\
\hline
\end{tabular}

\section{Discussion}

DME is a manifestation of diabetic retinopathy that produces severe visual impairment. Although several treatment modalities are under investigation the only demonstrated means to reduce the risk of vision loss from DME are laser photocoagulation, as demonstrated by the ETDRS2 and Anti-VEGF injections. Several recent systematic reviews of treatment options for Visual Impairment due to Diabetic Macular Edema have concluded that anti-VEGF therapies consistently demonstrated superior efficacy compared with alternative therapies. The results of the current systematic review and analysis confirm the findings of this trial demonstrating superiority of anti-VEGF monotherapy over laser monotherapy in the treatment of Visual Impairment due to Diabetic Macular Edema.

Study was conducted in 2018 in Madinah teaching hospital to evaluate the effect on patients with diabetic macular edema to comparison of anti VEGF and laser photocoagulation. The study design was interventional. Results of our study were concluded that Anti-VEGF is more significant to improve vision in diabetic macular edema patients than photocoagulation statistically. In 2014, research was published on a purpose to compare treatment patterns of AntiVEGF and Laser photocoagulation among the patients with diabetic macular edema. This randomized meta-analysis was conducted for the DME patients treated with laser or Anti-VEGF therapy. Study reported that Anti-VEGF therapies had superior efficacy to laser photocoagulation 9. Our study was in favors with this study.

Another Research was published in past years based on evaluating how monitoring and treatment for diabetic macular edema has changed. This retrospective cohort study concluded that Anti-VEGF has superior outcomes over laser Photocoagulation but laser was still used more frequently. ${ }^{10}$ This study was also supporting my study results that anti-VEGF gives more rapidly and good outcomes than photocoagulation. Our study was also concluded that Anti-VEGF is better than photocoagulation after conducted research in MTH in 2018. Both of these studies concluded that although Anti-VEGF use is increasing, laser use is still prevalent. A Study was published in 2017 evaluating the safety, efficacy and injection frequency of vascular endothelial growth factors (VEGF) inhibitors as used in clinical routine for treatment of diabetic macular edema. Multicenter, retrospective chart review was held in patients receiving anti-VEGF injections. This study reported that many patients were suboptimal responder to Anti-VEGF injections. Those patients who did not respond to Anti-VEGF required additional treatments such as laser or Intravitreal corticosteroid. ${ }^{11}$ But our study results were opposite to this study because our results describe that anti-VEGF is more effective.

\section{Conclusion}

According to my study there is greatest statistical difference in BCVA and macular thickness between laser photocoagulation and Anti VEGF (Bevacizumab). Visual acuity improved significantly after Anti VEGF Injections $(\mathrm{P}<0.05)$. In clinical practice our analysis confirms that intravitreal Bevacizumab is most favorable for BCVA improvement and macular thickness decrease compared with Laser therapy in the management of diabetic macular edema after 1 month follow up. VEGF inhibitors for diabetic macular edema should be used with caution due to systematic AEs. More high-quality randomized controlled trials will be necessary.Our results indicate that intravitreal bevacizumab injections may have a beneficial effect on macular thickness and VA, independent of the type of macular edema that is present (focal vs. diffuse). Therefore, in the future this new treatment modality could replace or complement focal/grid laser photocoagulation. Furthermore, focal/grid laser photocoagulation could be used to consolidate the results obtained with one intravitreal bevacizumab injection and decrease the need for reinjections.

\section{Acknowledgments}

None.

\section{Funding}

Authors don't have any financial disclosure.

\section{Conflicts of interest}

Authors don't have any conflict of interest. 


\section{References}

1. Meyer-Schwickerath G, Schott K. Diabetic retinopathy and photocoagulation. American Journal of Ophthalmology. 1968;66(4):597-603.

2. Zhang X, Saaddine JB, Chou CF, et al. Prevalence of diabetic retinopathy in the United States, 2005-2008. JAMA. 2010;304(6):649-656.

3. Davidov E, Breitscheidel L, Clouth J, et al. Diabetic retinopathy and health-related quality of life. Graefes Arch Clin Exp Ophthalmol. 2008;247(2):267-272.

4. Klein R, Klein B, Moss S, et al. The Wisconsin epidemiologic study of diabetic retinopathy. Arch Ophthalmol. 1984;91(12):1464-1474.

5. Patelli F, Faslino G, Radice P, et al. Time course of changes in retinal thickness and visual acuity after intravitreal triamcinolone acetode for diffuse macular edema with and without previous macular laser treatment. Retina. 2005;25(7):840-845.

6. Anonymous. Early Treatment Diabetic Retinopathy Study Research Group. Photocoagulation for diabetic macular edema. Early Treatment Diabetic Retinopathy Study report number 1. Arch Ophthalmol. 1985;103(12):1796-1806
7. Bandello F, Cunha-Vaz J, Chong N, et al. New approaches for the treatment of diabetic macular oedema: recommendations by an expert panel. Eye. 2012;26(4):485-493.

8. Joshi L, Bar A, Tomkins-Netzer $\mathrm{O}$, et al. Intravitreal bevacizumab injections for diabetic macular edema-predictors of response. Clin Ophthalmol. 2016;10:2093-2098.

9. Regnier S, Malcom W, Allen F, et al. Efficacy of anti-VEGF and laser photocoagulation in the treatment of diabetic macular edema. A systematic review and Meta-analysis. PLoS One. 2014; 9(7):e 102309.

10. VanderBeek B, Shah N, Parikh P, et al. Trends in the Care of diabetic macular edema: Analysis of a National Cohort. Plos one. 2016;11(2):149-450

11. Blinder $\mathrm{K}$, Dugel $\mathrm{P}$, Chen $\mathrm{S}$, et al. Anti-VEGF treatment of diabetic macular edema in clinical practice: effectiveness and patterns of use (ECHO Study Report 1). Clin Ophthalmol. 2017;11:393-401. 